\title{
HEAVY METAL SORPTION USING THIOLATED OILS OF ELAEIS GUINEENSIS AND GLYCINE MAX
}

\author{
Onyeka Stanislaus Okwundu *, Chibuzor Kelvin Enyekwe, Chinedu James \\ Chiama, Chimezie John Chiama, Obiora Ebuka Muojama, Chukwujekwu \\ Augustine Okaro, Cyril Oluchukwu Ugwuoke, Ekene Kingsley Uzoma \\ Science and Engineering Unit, Nigerian Young Researchers Academy, Awka Road, \\ 430231 Onitsha North Local Government Area, Anambra State, Nigeria
}

Received 14.07.2020

Accepted 24.08.2020

\begin{abstract}
Sulphur-modification of matter confers improved heavy metal affinity and could be exploited in the treatment of heavy metal contaminated water. This paper is aimed at comparing the liquid-liquid $\mathrm{Ag}^{+}$sorption capacities of normal and thiolated: palm oil (PO), palm kernel oil (PKO) and soybean oil (SBO), respectively. The vegetable oils were modified with 1-heptanethiol, and the thioether-functionalized (TF) oils were utilized for the removal of $\mathrm{Ag}^{+}$present as a contaminant in water, while the unmodified oils acted as controls. The liquid-liquid equilibrium contact time was determined to be 6 hours. The result achieved after equilibration revealed the effectiveness of TF oils in the removal of $\mathrm{Ag}^{+}$from a $600 \mathrm{ppm} \mathrm{AgNO}_{3}$ simulated water. While TF-SBO reduced the cation concentration to a level less than the detection limit, TF-PKO only showed appreciable sorption capacity (below 30\%) relative to the normal oils. The order of $\mathrm{Ag}^{+}$sorption capacity (TF-SBO > TF-PO > TF-PKO) was ascribed to various levels of unsaturation of fatty acid chains encountered in the lipids. A higher number of sorption-active TF sites is achievable with a greater degree of fatty acid unsaturation. On that note, highly unsaturated vegetable oils (such as that of Glycine max) were recommended.
\end{abstract}

Keywords: sulphur-functionalized lipids; palm oil; palm kernel oil; soybean oil; liquid-liquid sorption; fatty acid unsaturation; heptanethiol; extraction; $\mathrm{Ag}^{+}$remediation; water treatment.

${ }^{*}$ Corresponding author: Onyeka Stanislaus Okwundu, onyeka.okwundu@eng.uniben.edu 


\section{Introduction}

Human activities, such as industrialization, have led to an increase in the concentration of heavy metals present in the environment. This poses a great threat to mankind, as well as the land and sea animals [1]. Notwithstanding, heavy metals (both in the elemental and combined states) are indispensable in the processing industry. Two of their vital applications include that they catalyze a variety of chemical reactions [2-4]. In the field of electrochemistry, pseudocapacitors could not have existed without the application of heavy metal oxides as electrochemically active electrodes [5]. Complete removal or reasonable reduction in the concentration of heavy metals like mercury, silver, lead, etc. in industrial waste (be it gaseous, liquid, or solid) before disposal, is ethical and eco-friendly. As water is essential for life, several techniques have been utilized effectively for remediation of heavy metal contaminated water. Such techniques include extraction, adsorption, chemical precipitation, ion exchange, membrane processes (reverse osmosis, electrodialysis, ultrafiltration, nanofiltration), coagulation, flocculation, floatation [6], and even biologically via phytoremediation [7].

Nowadays, these heavy metal sequestration processes are administered with the introduction of sulphur. Efficient and selective adsorption of noble metals has been achieved using hydrophilic sulphur-containing adsorbents prepared via radical terpolymerization of a methacrylate associated dithiocarbonate moieties [4]. Also, the use of carbon nanotubes grafted with thiol and dithiocarbamate ligands [8] and some sort of sulphide [9] support this fact. Several other types of research [10-12] on heavy metal remediation have been carried out by treating contaminated water with sulphur-modified agents. Moreover, in the course of phytoextraction of heavy metal in municipal sewage sludge, the introduction of elemental sulphur improved heavy metal uptake by plants [13]. While the exact interactions between various sulphur functionalities and heavy metals are not clearly understood [14], it is generally accepted that sulphur functionalities have a strong affinity for heavy metals $[4,14-18]$.

Murray et al. [15] discovered that solid, liquid or gaseous materials contaminated with heavy metals could be treated by contacting such materials with a thiolfunctionalized fatty acid or thiol-functionalized ester of fatty acids (sulphur-modified biooil) for a while, under certain conditions effective for the sequestration of the metal species by the modified organic liquid. Since its discovery, research in this direction has been exclusively reserved for the patent owners, as though they monopolized it. Meanwhile, Bantchev et al. [19] have investigated "Free radical addition of butanethiol to vegetable oil double bonds", establishing a means to thioether-functionalized vegetable oil (TF-VO) synthesis in the presence of ultraviolet radiation at wavelength, $\lambda<325 \mathrm{~nm}$ and the reaction scheme is as shown in Equation 1. Murray and co-workers have limited their studies to only two highly unsaturated oils (canola oil and/or corn oil) $[15,16,20]$. Such extractive sorption studies with oils of various levels of fatty acid unsaturation have not been experimentally instigated.

$$
\text { Vegetable oil }+ \text { Alkanethiol } \stackrel{U V}{\longrightarrow} \text { Thiolated oil }
$$


Dating back to antiquity, Ag has been such a precious metal, usually ranked right after Au. Also, considering its attractive characteristic optical properties, unrivaled electrical and thermal conductivities, and reduction (electrochemical) potential of $+0.8 \mathrm{~V}$. $\mathrm{Ag}$, as well as its compounds finds application in the making of jewelries and ornaments, in photography, in mirror production, in electronics (where it serves as ideal conductor for printed circuit boards), in electrochemistry (where it is used for battery electrode, for electroplating, as reference electrode in the 3-electrode testing system and in potentiometric $\mathrm{pH}$ measuring devices, as oxidation or corrosion resistant material), etc. [3, 21-23]. Moreover, Ag has inherent antimicrobial properties, and therefore used for disinfection, hygiene, personal care, and healthcare [24-26]. The common soluble form of $\mathrm{Ag}$ is its nitrate salt. With all the applications mentioned above, discharge of $\mathrm{Ag}$ into the environment as particulate matter (elemental, compound, or alloy form) or as dissolved matter, is inevitable.

Studies (in vivo and in vitro) have shown that Ag can accumulate in various organs (skin, liver, lungs, brain, gut, kidney, etc.), including the blood of exposed animals [25]. Toxicological effects arising from chronic exposure to particulate or ionic Ag include discoloration of the eyes (argyrosis) or/and skin (argyria); while the ionic Ag is further reported to cause: damages to liver and kidney, irritation of the eyes, skin, respiratory, and intestinal tract, and alteration of blood cells [23]. Beyond the direct impact on exposed individuals, both the particulate and ionic forms of $\mathrm{Ag}$ can adversely affect the development of embryonic stem cells [27]. Soil and aquatic lives are as well affected adversely [1]. These led the US Environmental Protection Agency [28] to set a maximum contaminant level of $0.1 \mathrm{ppm}$ for $\mathrm{Ag}$, in drinking water. Since we can barely quit using $\mathrm{Ag}$, remediation strategies are therefore necessary. Besides, the few available works [16, 20] on heavy metal remediation by extraction using TF-VOs employed Ag; we also employ Ag in order to have a basis for result comparison.

Based on the foregoing, this work is aimed at comparing the liquid-liquid sorption capacities of normal and thiolated: palm oil (PO), palm kernel oil (PKO), and soybean oil (SBO), respectively, in the extraction of silver ions from simulated (self-induced) wastewater. These oils have quite distinct degrees of unsaturation and have not been tried in this application. We intend to see how the degree of unsaturation affects the performance of oils in this application and the possibility of utilizing other oils $[15,16$, 20]. The outcome of our investigation would influence one's choice of oil for heavy metal sorption. This study is further justified by the fact that it supports a healthy ecosystem; meanwhile, bio-oils are environmentally sustainable and renewable.

\section{Materials and Methods}

\section{Characterization of oil samples}

Two kinds of vegetable oil derived from the fleshy fruits and seeds of Elaeis guineensis (PO and PKO, respectively) were donated by local farmers in Abatete, Anambra State, while SBO was purchased from Ose Market, Anambra State, Nigeria.

The vegetable oil samples were analyzed for the following physicochemical properties: acid value, saponification value, iodine value, moisture content, density, kinematic viscosity, appearance, flash point, fire point, and fatty acid profile, as described elsewhere [29]. 
Sulphur-modification of vegetable oil samples

Part of each sample in Sect. 2.1 was modified by reacting each, respectively, with excess 1-heptanethiol in the presence of ultraviolet light (UV at a wavelength of $300 \mathrm{~nm}$ ) such that they become thioether functionalized (TF) [19]. In a typical modification experiment, $100 \mathrm{~g}$ of oil was reacted with $30 \mathrm{~g}, 20 \mathrm{~g}$, or $65 \mathrm{~g}$ of heptanethiol to obtain crude TF-PO, TF-PKO, or TF-SBO, respectively. Thereafter, the modified oil (TF-VO) samples were respectively recovered from the crude mixture (with excess/unreacted heptanethiol) by simple distillation. The sulphur-modification reaction is as given in Figure 1.

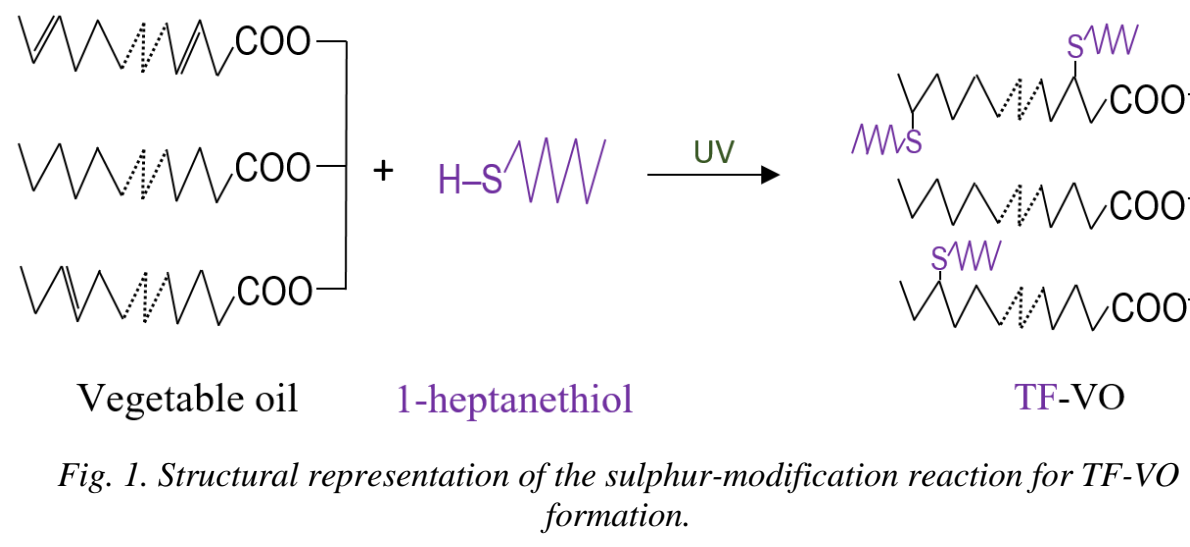

\section{Liquid-liquid sorption experiments}

$\mathrm{AgNO}_{3}$, a product of Sigma Aldrich, was used to introduce Ag contamination in water. A stock $600 \mathrm{ppm}$ aqueous solution of $\mathrm{AgNO}_{3}$ was prepared using deionized water. Cation extraction experiments were carried out using $20 \mathrm{~mL}$ of the contaminated water for each run.

Determination of equilibrium contact time

First, the equilibrium liquid-liquid contact time was determined by adding roughly $3.5 \mathrm{~g}$ of each of the TF oil samples, respectively, to $20 \mathrm{~mL}$ of contaminated water in masked conical flask mounted on a stirrer, all within an enclosed dark chamber, due to the light sensitivity of silver salts. In each case, the resulting two-phase mixture was maintained at a temperature of $300 \mathrm{~K}$ and stirred at $200 \mathrm{rpm}$ for up to 10 hours. In the interim of stirring, samples were taken after $0.5,1,2,4,6,8$, and 10 hours and then separated. Treated water samples were collected from the clear aqueous layer recovered after centrifugation of the stirred oil-water mixture. Inductively Coupled Plasma Mass Spectrometer (ICPMS-2030 Shimadzu) was used to analyze the water samples, at $328 \mathrm{~nm}$ [16], while a commercial standard Ag solution (QMX Laboratories Ltd, UK) was used for calibration. $\mathrm{Ag}^{+}$sorption efficiency was calculated according to Equation $2 \mathrm{a}$. Where $\left[\mathrm{Ag}^{+}\right]_{0}$ and $\left[\mathrm{Ag}^{+}\right]_{t}$ are the initial and instantaneous concentrations of the metallic ion in water.

$$
\text { Sorption efficiency }(\%)=\frac{\left[\mathrm{Ag}^{+}\right]_{0}-\left[\mathrm{Ag}^{+}\right]_{t}}{\left[\mathrm{Ag}^{+}\right]_{0}} \times 100
$$


Determination of extractive sorption capacities

In order to determine the respective sorption capacities, various amounts of the vegetable oils in the range of 0.1 to $10 \mathrm{~g}$, they were respectively added to $20 \mathrm{~mL}$ of contaminated water and brought to equilibrium (stirred for the determined equilibrium contact time/period). Separation and analysis of treated water were performed, as described in Section 2.3.1. In this case, however, normal oils were also considered. $\mathrm{Ag}^{+}$ sorption efficiency was calculated according to Equation $2 \mathrm{~b}$. Where $\left[\mathrm{Ag}^{+}\right]_{e q}$ is the equilibrium concentration of the metallic ion in water - as determined in Section 2.3.1.

$$
\text { Sorption efficiency }(\%)=\frac{\left[\mathrm{Ag}^{+}\right]_{0}-\left[\mathrm{Ag}^{+}\right]_{e q}}{\left[\mathrm{Ag}^{+}\right]_{0}} \times 100
$$

\section{Results and discussion}

The physicochemical properties of vegetable oils

Analyses of the normal/raw vegetable oils resulted in the physicochemical properties shown in Table 1. Oil is a mixture of organic compounds (predominantly, fatty acid esters of glycerol) and from the table, the oil samples had viscosities greater than water (about $1 \mathrm{~mm}^{2} / \mathrm{s}$ ) and densities less than water (about $1000 \mathrm{~kg} / \mathrm{m}^{3}$ ); therefore, when contacted with water, the mixture could be readily separated by centrifugation. The oil samples had considerably low acid value - an indication of good/unimpaired quality; such oils can readily be transesterified for biodiesel production [29]. The relatively high saponification value of PKO is an indication of relatively short fatty acid chains; moreover, the three samples had high saponification values, and therefore suitable for soap-making [30]. The iodine values measure their various levels of fatty acid saturation [29], with PKO being the most saturated, and SBO, the least (the most unsaturated). Considering the fatty acid profile, the PKO was composed of the shortest fatty acid chains with only $9 \%$ unsaturation - fewest thiolation (reaction) sites. On the other hand, SBO had the longest of chains and the highest level of unsaturation (more than $80 \%$ ). The respective iodine values confirmed the order of fatty acid unsaturation to be $\mathrm{PKO}<\mathrm{PO}<$ SBO. The flash and fire points are fuel properties - measures of fuel flammability and flame sustainability, respectively. The values obtained in this study are quite high, guaranteeing safety in handling and storage [29]. 
Table 1. Physicochemical properties of the normal vegetable oils.

\begin{tabular}{llll}
\hline & PO & PKO & SBO \\
\cline { 2 - 4 } Acid value $(\mathrm{mg} \mathrm{KOH} / \mathrm{g})$ & 1.85 & 0.88 & 1.20 \\
Saponification value $(\mathrm{mg} \mathrm{KOH} / \mathrm{g})$ & 174.3 & 237.0 & 151.6 \\
Iodine value $(\mathrm{g} \mathrm{I} / 100 \mathrm{~g})$ & 53.8 & 18.4 & 135.3 \\
Moisture content $(\mathrm{wt} . \%)$ & 1.01 & 0.12 & 0.07 \\
Actual density at $28^{\circ} \mathrm{C}\left(\mathrm{kg} / \mathrm{m}^{3}\right)$ & 920.96 & 913.72 & 916.08 \\
Kinematic viscosity at $28^{\circ} \mathrm{C}\left(\mathrm{mm}^{2} / \mathrm{s}\right)$ & 30.13 & 29.42 & 28.94 \\
Appearance & red & Brownish & Yellowish \\
Flash point $\left({ }^{\circ} \mathrm{C}\right)$ & 319 & 314 & 319 \\
Fire point $\left({ }^{\circ} \mathrm{C}\right)$ & 353 & 348 & 350 \\
Fatty acid profile & & & \\
\hline Caproic acid, C6:0 $(\%)$ & - & 0.2 & - \\
Capryric acid, C8:0 $(\%)$ & - & 5.2 & - \\
Capric acid, C10:0 $(\%)$ & - & 4.7 & - \\
Lauric acid, C12:0 $(\%)$ & - & 62.4 & - \\
Myristic acid, C14:0 $(\%)$ & 1.2 & 12.9 & - \\
Palmitic acid, C16:0 $(\%)$ & 41.8 & - & 7.2 \\
Palmitoleic acid, C16:1 $(\%)$ & 0.3 & - & - \\
Stearic acid, C18:0 $(\%)$ & 3.9 & - & 3.3 \\
Oleic acid, C18:1 $(\%)$ & 38.5 & 6.0 & 20.9 \\
Linoleic acid, C18:2 $(\%)$ & 10.7 & - & 56.8 \\
Linolenic acid, C18:3 $(\%)$ & 1.1 & & 8.1 \\
\hline
\end{tabular}

\section{Liquid-liquid equilibrium contact time}

Furthermore, to ascertain the liquid-liquid equilibrium contact time, the influence of contact time on $\mathrm{Ag}^{+}$sequestration at TF-VO loading of $3.5 \mathrm{~g}$ per $20 \mathrm{~mL}$ of contaminated water, was investigated at $300 \mathrm{~K}$, and the result is as shown in Figure 2. From the figure, TF-PKO quickly attained a stable extraction efficiency after 4 hours, while other TF-VOs reached 6 hours. The early equilibration observed for TF-PKO could be linked to its relatively low sorption capacity. By introducing a minute pre-vortexmixing stage, Murray et al. [16] achieved faster equilibration (within 3 hours), using 0.3 $\mathrm{g}$, each of TF-corn oil and TF-canola oil in $3 \mathrm{~mL}$ of $600 \mathrm{ppm} \mathrm{Ag}$ contaminated water. However, in another study [20], even with pre-vortex-mixing, equilibrium in $\mathrm{Ag}$ concentration could not be reached in less than 6 hours, with the co-existence of $\mathrm{Hg}$ ions. On the other hand, for liquid-solid adsorption, typical equilibrium contact time ranges from 0.25 to 2.5 hours [22, 31]. It should be noted, however, that this liquid-liquid sorption is still untapped. For this study, a general equilibrium contact time of 6 hours was chosen and used hereafter. 


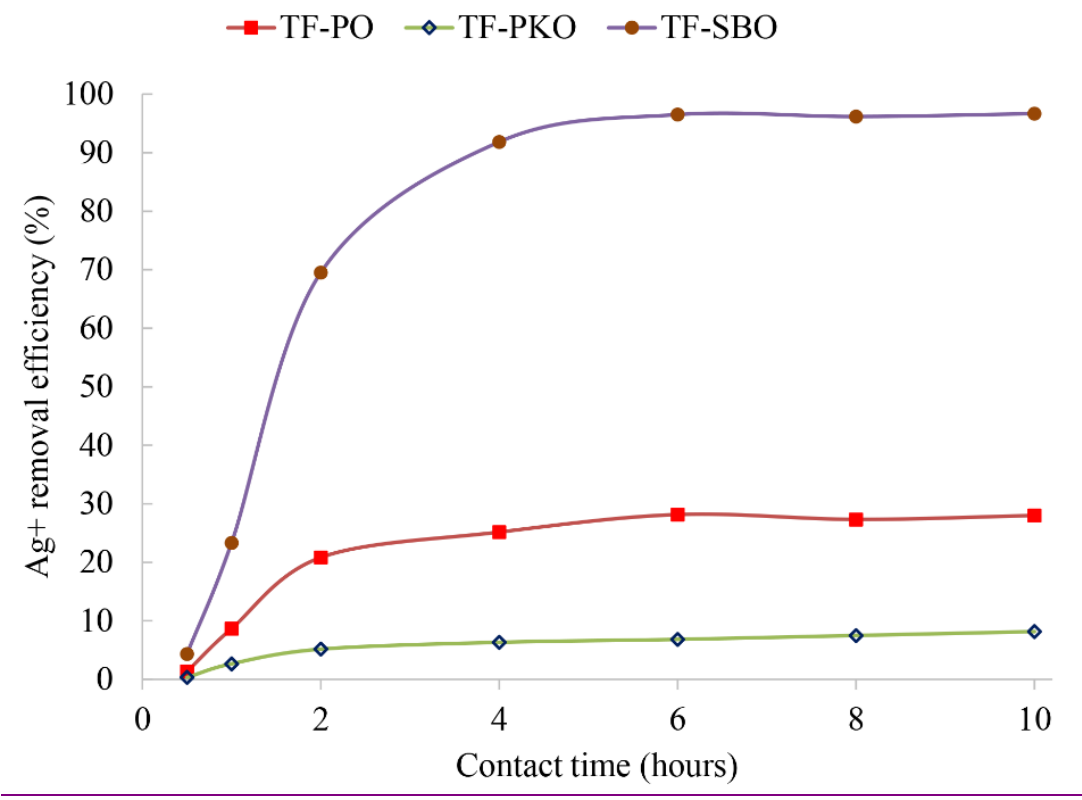

Fig. 2. Influence of contact time on the Ag+ sequestration at TF-VO loading of $3.5 \mathrm{~g}$ per $20 \mathrm{~mL}$ of contaminated water.

Liquid-liquid sorption capacities of various (normal and TF) oil samples

Now, considering the cation removal efficiency of both the normal and TF oils, Figure 3 gives the comparative extraction capacities of the normal and TF oils. All normal oils were inefficient. TF-SBO was outstanding at all investigated concentrations, attaining $100 \% \mathrm{Ag}^{+}$removal efficiency at a loading of $5 \mathrm{~g}$ per $20 \mathrm{~mL}$ of contaminated water. It reduced the $\mathrm{Ag}^{+}$concentration to a value of less than $0.5 \mathrm{ppm}$ (the detection limit of the analytical device). This extraction performance was maintained as the oil loading was increased up to $10 \mathrm{~g}$. TF-PO followed after with a somewhat linear trend up to $8 \mathrm{~g}$ oil loading, but its extraction capacity did not exceed $70 \%$. TF-PKO had the least sorption capacity of all the TF-VOs. Considering the nature of the vegetable oils, SBO had the highest concentration of double bonds (unsaturation), which is necessary for thiol-ene addition reaction. Hence, TF-SBO had the highest active sorption (TF) site concentration for heavy metal removal. The normal oils lacked such a site, and TF-PO had much of it than TF-PKO. With reference to Figure 2, the poor concentration of sorption sites in TFPKO, or better said, the presence of only a few sites in TF-PKO could have caused it to attain equilibrium earlier than TF-PO and TF-SBO, since less $\mathrm{Ag}^{+}$needed to be captured to saturate the functionalized sites. 


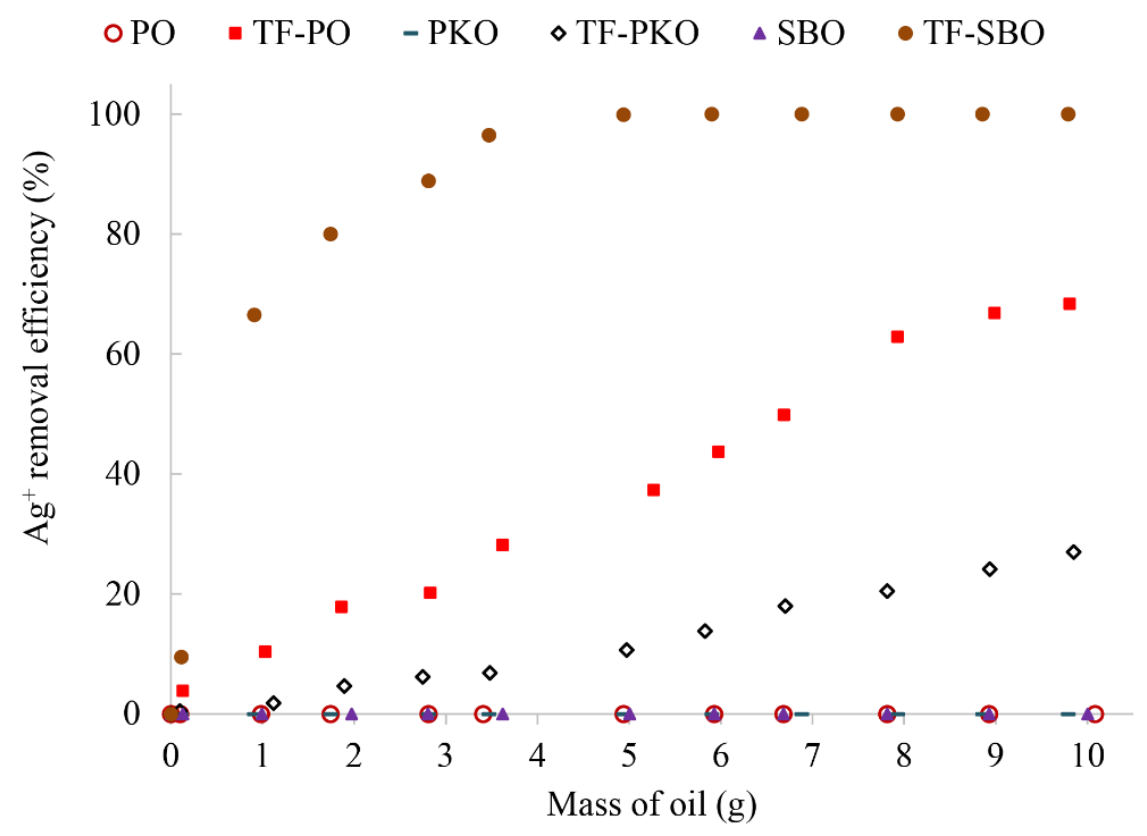

Fig. 3. Comparative extraction capacities of the normal and TF oils.

Economically speaking, the use of TF-SBO would save more oil due to its relatively high sorption capacity -only a little amount was needed to achieve the highest cation removal efficiency. Moreover, this would reduce the amount of used oil emanating from the process.

Lastly, earlier reports on the Ag-sorption capacity of butanethiol-functionalized oils show $60.8 \%$ efficiency for $104 \mathrm{mg}$ TF-canola oil in $1 \mathrm{~mL}$ contaminated water [16]. The performance of TF-SBO from this study is comparable to that of TF-canola oil [16], while TF-PO and TF-PKO are less effective. The use of raw oils in this regard only served as a control experiment.

\section{Recommendations}

Future works should focus on optimizing the extraction process, and investigating the liquid-liquid adsorption kinetics. This study relied on bench-scale experiments. It is also necessary to determine the effects of stirring speed and other process conditions (temperature, $\mathrm{pH}$, contaminant loading/concentration, kind of sulphur-containing group used for oil functionalization, etc.) on the extraction process in order to optimize the use of TF-VO in extracting heavy metals. Moreover, investigation of the process kinetics would pave the way for understanding the mechanism of the liquid-liquid ion sorption.

Meanwhile, implementation of the outcome of this study in remediating heavy metal-contaminated water is recommendable and is already in progress. We propose a heavy metal remediation plant based on the process flow diagram shown in Figure 4. TFVO would be prepared or purchased and stored. Contaminated water and TF-VO would be pumped respectively to the arms of a long passive T-mixer with post-confluence bends 
(M-1). Studies have shown that this kind of mixer is very effective for contacting fluid phases down to the molecular level $[32,33]$. Further mixing could be achieved with an active stirred tank with a residence time of about 1 hour, as against the 6 hours needed to achieve equilibrium in this study. The mixed fluid could be separated using a hydrocyclone (or series of it, if necessary) at high feed pump pressure. It is recommended that used TF-VO (with trapped metals) be regenerated and recycled for process sustainability.

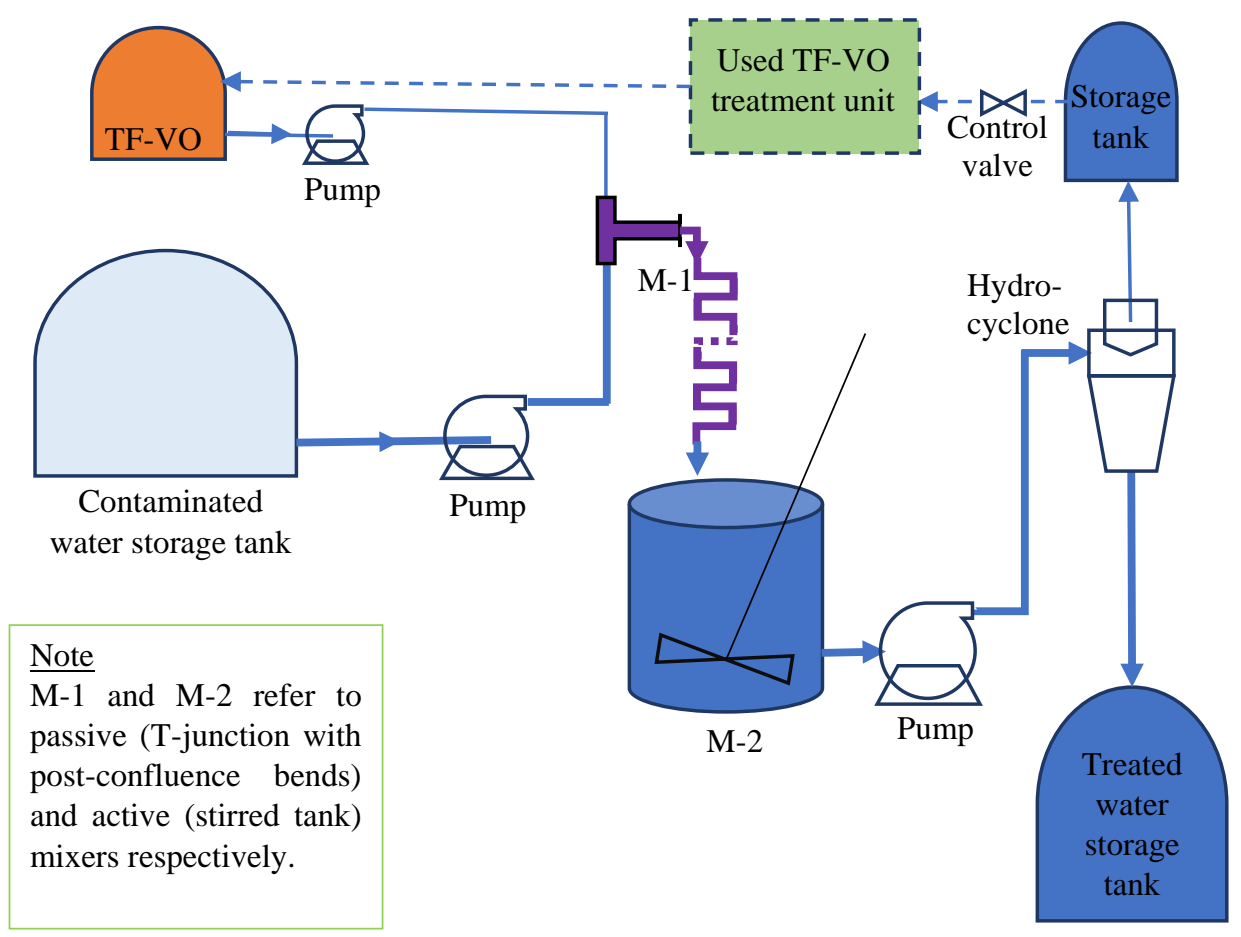

Fig. 4. Process flow diagram of the proposed heavy metal remediation plant.

\section{Conclusion}

In this study, the liquid-liquid $\mathrm{Ag}^{+}$sorption capacities of normal and thiolated oils derived from untried sources (Elaeis guineensis and Glycine max), namely: palm oil (PO), palm kernel oil (PKO) and soybean oil (SBO), respectively, have been compared. It was found that TF-SBO had the highest sorption capacity, followed by TF-PO and then TF$\mathrm{PKO}$, while the normal oils were ineffective. Based on the conditions employed (600 ppm silver contaminated water), TF-SBO was found capable of completely trapping $\mathrm{Ag}^{+}$ present in water. Sulphur-modification of oils renders them effective for the extraction of heavy metals like silver in aqueous media. The concentration of heavy metal sorptionactive (TF) sites in the sulphur-modified oil, favorably determines its sorption capacity, and greater sites are formed with oils of high fatty acid unsaturation. Consequently, for water treatment application, the choice of bio-oil for sulphur-modification should be one with relatively high total unsaturated bonds. 


\section{References}

[1] C.A. Ottoni, M.C. Lima Neto, P. Léo, B.D. Ortolan, E. Barbieri, A.O. De Souza: Chemosphere, 239 (2020) 124698.

[2] O.S. Okwundu, E.U. Aniekwe, C.E. Nwanno: Metall Mater Eng, 24 (2018) 145171.

[3] Y. Zhang, A. Ye, Y. Yao, C. Yao: Sensors, 19 (2019) 247.

[4] H. Kinemuchi, B. Ochiai: Adv Mater Sci Eng, 2018 (2018) 54-60.

[5] O.S. Okwundu, C.O. Ugwuoke, A.C. Okaro: Metall Mater Eng, 25 (2019) 105138.

[6] K.C. Khulbe, T. Matsuura: Appl Water Sci, 8 (2018) 19.

[7] T. Mishra, V.C. Pandey, A. Praveen, N.B. Singh, N. Singh, D.P. Singh: Environ Geochem Health (2020) 1-11.

[8] A.K.S. Deb, N. Dhume, K. Dasgupta, S.M. Ali, K.T. Shenoy, S. Mohan: Sep Sci Technol (2018) 1-15.

[9] W. Fu, H. Chen, S. Yang, W. Huang, Z. Huang: Chemosphere, 232 (2019) 9-17.

[10] A.T. Yordanov, B.R. Whittlesey, D.M. Roundhill: Inorg Chem, 37 (1998) 35263531.

[11] K. Chayama, Y. Morita, S. Iwatsuki: J Chromatogr A, 1217 (2010) 6785-6790.

[12] T.F. Baumann, J.G. Reynolds, G.A. Fox: React Funct Polym, 44 (2000) 111-120.

[13] G. Dede, S. Ozdemir: J Environ Manage, 166 (2016) 103-108.

[14] D. Saha, S. Barakat, S.E. Van Bramer, K.A. Nelson, D.K. Hensley, J. Chen: ACS Appl Mater Interfaces, 8 (2016) 34132-34142.

[15] R.E. Murray, G.B. Bantchev, K.M. Doll, R.O. Dunn, K.L. Ascherl, Heavy Metal Remediation via Sulfur-Modified Bio-Oils, WO 2014/089428 A1, 2014.

[16] R.E. Murray, G.B. Bantchev, R.O. Dunn, K.L. Ascherl, K.M. Doll: ACS Sustain Chem Eng, 1 (2013) 562-565.

[17] W. Yantasee, C.L. Warner, T. Sangvanich, R.S. Addleman, T.G. Carter, R.J. Wiacek, G.E. Fryxell, C. Timchalk, M.G. Warner: Environ Sci Technol, 41 (2007) 5114-5119.

[18] L. Mercier, T.J. Pinnavaia: Environ Sci Technol, 32 (1998) 2749-2754.

[19] B.G. Bantchev, A.J. Kenar, G. Biresaw, G.M. Han, J. Agric: Food Chem, 57 (2009) 1282-1290.

[20] R.O. Dunn, G.B. Bantchev, R.E. Murray, K.M. Doll, K.L. Ascherl, J.C. Lansing: J Am Oil Chem Soc, 95 (2018) 1189-1200.

[21] L. Manjakkal, D. Szwagierczak, R. Dahiya: Prog Mater Sci, 109 (2020) 100635.

[22] T. Jintakosol, W. Nitayaphat: Mater Res, 19 (2016) 1114-1121.

[23] P.L. Drake, K.J. Hazelwood: Ann Occup Hyg, 49 (2005) 575-585.

[24] V. Edwards-Jones: Lett Appl Microbiol, 49 (2009) 147-152.

[25] L. Fewtrell, Silver: Water Disinfection and Toxicity, 2014.

[26] P. Staroń, K. Pszczółka, J. Chwastowski, M. Banach: Environ Sci Pollut Res (2020) 1-13.

[27] X. Gao, V.D. Topping, Z. Keltner, R.L. Sprando, J.J. Yourick: J Nanobiotechnology, 15 (2017) 1-18.

[28] Office of Water United States Environmental Protection Agency, EPA (2020).

[29] O.S. Okwundu, Biodiesel Production from Animal Fat Using Calcium-Based Catalysts, Egypt-Japan University of Science and Technology, Egypt, 2019.

[30] Food Safety and Standards Authority of India, Oils and Fats, New Delhi, India, 2015. 
[31] J.A. Hefne, W.K. Mekhemer, N.M. Alandis, O.A. Aldayel, T. Alajyan: J King Saud Univ Sci, 22 (2010) 155-176.

[32] N. Aoki, R. Umei, A. Yoshida, K. Mae: Chem Eng J, 167 (2011) 643-650.

[33] O.S. Okwundu, M. Fuseini, Characterization of Mixing Performance of Micromixers : Effect of Confluence Shape and Normal Bends after Confluence, 2018.

$$
\text { (c) (7) Creative Commons License }
$$

This work is licensed under a Creative Commons Attribution 4.0 International License. 